\title{
Editorial: Industrial networks for resource efficiency
}

Emilia den Boer Mgr Inz, MSc, Dr Inz

Assistant Professor, Wroclaw University of Technology, Institute of Environment Protection Engineering, Wroclaw, Poland

Ian D. Williams PhD, PGCE, CChem, MRSC, MCIWM, FHEA

Professor, Centre for Environmental Sciences, Faculty of Engineering and

the Environment, University of Southampton, Southampton, UK
Tony Curran MRes, PhD, LCGI

Research Fellow, Centre for Environmental Sciences, Faculty of Engineering and the Environment, University of Southampton, Southampton, UK

Bernd Kopacek MSC

Managing and Research Director, Austrian Society for Systems Engineering and Automation (SAT), Vienna, Austria
Wasted materials represent valuable resources that we can no longer afford to discard. The concept of 'zero waste' is a challenge to old ways of thinking, calling for waste to be viewed as a potential resource with value to be realised, rather than as a problem to be dealt with, usually by burial in landfill sites or incineration without energy recovery. Examples of industrial symbiosis - the theoretical rationale and methods for sharing information and resources across different industries are starting to be found worldwide. In this themed issue, we focus on technological issues. A short overview of the themes that are discussed in detail in the individual papers is given below. The key concepts of the Zerowin vision (outlined in the briefing by den Boer et al. (2014)) formed the foundation of the demonstration case studies presented in this journal.

One of the methods deemed promising for the zero waste strategies is the holistic design for recycling, repair, refurbishment and reuse (D4R). Two of the Zerowin case studies apply this methodology for high-tech products: a laptop and a photovoltaic (PV) system.

The D4R laptop case study (Hickey et al., 2014) has demonstrated an industrial network established by a laptop manufacturer MicroPro with end-of-life IT asset management firms, IT refurbishers, component manufacturers and local industries. The innovative idea was to develop a laptop design that allows the creation of a new life for the used IT components, thus turning wastes into products. MicroPro has successfully been able to manufacture a universal shell that is capable of accepting new primary system components and also has the ability to integrate various parts and components (and parts and components of different specifications).

The focus of the second case study is a D4R PV system (Arranz et al., 2014). Here, a Zerowin industrial network allowing higher resource efficiency was developed around the PV system prototype, which, at the same time, was designed to operate more efficiently. The demonstration of the PV system case study was carried out in two phases: the first phase concerned the redesign of the power conditioning equipment according to the D4R strategies. The second phase was the demonstration of the D4R design of: (a) a gridconnected PV system at the energy provision company and (b) a stand-alone system installed at the recycling company, both in Spain. The development of the prototype focused on the improvement of the overall PV system efficiency (performance ratio (PR)), the increase of the operational lifetime, the improvement of the overall PV system condition monitoring and the increase of the reliability of the equipment. Improving the PR and the operational lifetime of the different components will enable the reduction of the use of batteries and PV modules - the main contributors of the PV system environmental impacts.

The first and second case studies are directly linked to the third ReUse network (Dietrich et al., 2014). The ReUse network is a value-conservation network that focuses on processes such as reuse, refurbishment and recycling within industrial networks. During the Zerowin project, the ReUse ICT network grew by involving new partners (approximately 50 network partners, mostly from ICT, automotive sectors and mechanical engineering) and 15 organisations, that offered data about used ICT equipment, scrap paper/cardboard, scrap plastics, wood off-cuts and scrap metals. The ReUse ICT network developed a qualitycontrol scheme and its own label, which ensures higher confidence in the reused equipment. An internet portal - the resource exchange platform - is an essential outcome of CS3, offering additional business opportunities through clustering of re-use firms, allowing regional transfer of the ReUse ICT concept, the inclusion of further product categories and the affiliation of additional service offers (for example, transportation of re-use or end-of-life products, take-back, service instead of sales).

The Zerowin case studies provide insight into the challenges and obstacles existing in the studied industry sectors. They should be seen as good lessons learned from the merging of academic theory and vision with industrial practice, and should 
Waste and Resource Management

Volume 167 Issue WR3
Editorial

den Boer, Williams, Curran and

Kopacek provide both objective evidence and inspiration for the future development of a resource efficient Europe.

\section{REFERENCES}

Arranz P, Anzizu M, Pineau A et al. (2014) The development of a resource-efficient photovoltaic system. Proceedings of the Institution of Civil Engineers - Waste and Resource Management 167(3): 109-122, http://dx.doi.org/10.1680/warm.13.00027. den Boer E, Williams ID, Curran T and Kopacek B (2014) Briefing: Demonstrating the circular resource economy - the Zerowin approach. Proceedings of the Institution of Civil
Engineers - Waste and Resource Management 167(3): 97 100, http://dx.doi.org/10.1680/warm.14.00005.

Dietrich J, Becker F, Nittka T et al. (2014) Extending product lifetimes: a reuse network for ICT hardware. Proceedings of the Institution of Civil Engineers - Waste and Resource Management 167(3): 123-135 http://dx.doi.org/10.1680/ warm.13.00024.

Hickey S, Fitzpatrick C, Maher P et al. (2014) A case study of the D4R laptop. Proceedings of the Institution of Civil Engineers - Waste and Resource Management 167(3): 101108, http://dx.doi.org/10.1680/warm.13.00031. 